\title{
Genetic variation in a modifier system affecting the expression of Bare mutant of Drosophila subobscura
}

\author{
G. Alvarez, \\ P. Martínez and \\ C. Zapata
}

Departamento de Biología Fundamental, Facultad de Biología, Universidad de Santiago de Compostela, Santiago de Compostela, Spain.

Genetic variation affecting the expression of Bare $(\mathrm{Ba})$, a morphological mutant of Drosophila subobscura that reduces the number of bristles and is located on the $\mathbf{O}$ chromosome of this species, is reported. Our results show that $O$ chromosomes extracted from a natural population (El Pedroso, Santiago de Compostela, Spain) show considerable genetic variation in modifier effect upon $B a$ expression. The amount of modifier variability is dependent on the chromosomal arrangement $\left(\mathrm{O}_{\mathrm{ST}}\right.$ and $\left.\mathrm{O}_{3+4+7}\right)$, since modifier variation is higher in $\mathrm{O}_{\mathrm{ST}}$ than in $\mathrm{O}_{3+4+7}$ chromosomes. Investigations of the genetic architecture of this modifier system on the $O$ chromosome carried out using biometrical methods indicate that a relatively small number of genetic "factors" can explain the differences in modifier effect between a wild $O$ chromosome of high modifier effect and a marker chromosome of low score. In addition, the modifier effects show a non-uniform distribution along the $\mathbf{O}$ chromosome and some indication of clustering of modifier "factors" around the major locus $(B a)$ is also observed.

\section{INTRODUCTION}

Modifier genes are usually considered to play an important role in adaptation (Feldman and Krakauer, 1976; Turner, 1977; Templeton, 1982), but, in spite of this, genetic variation in natural populations for these kind of genes is yet poorly known. Modifiers of expression of morphological mutants and genetic modifiers of enzyme activity are the main types of modifiers that have been studied (Thompson and Thoday, 1972; Thompson, 1973, 1974, 1975; Laurie-Ahlberg et al., 1982; Wilton et al., 1982; Tepper et al., 1982, 1984; Geer and Laurie-Ahlberg, 1984; Thompson and Spivey, 1984). Modifiers of mutant expression appear to be typical polygenes that generally act upon the character rather than affect only a specific mutant (Thompson, 1973, 1974, 1975a), although mutantspecific modifier effects have also been reported (Scharloo, 1964; Fraser, 1968). The importance of modifiers of mutant expression with respect to phenomena such as evolution of dominance (see Sved and Mayo, 1970), canalization and development (Rendel, 1979; Thompson and Woodruff, 1982) and mimicry (Turner, 1977) has been widely discussed. Nowadays, however, there is very little information about the extent of genetic variation for modifiers of mutant expression in natural populations although some efforts have been addressed to this subject (Alvarez et al., 1980; Thoday and Thompson, 1984; Thompson and Spivey, 1984).

Genetic variation in the phenotypic expression of Bare $(B a)$, a morphological mutant that reduces the number of bristles and is located on the $\mathrm{O}$ chromosome of Drosophila subobscura, has been found (Alvarez et al., 1980). Our early experiments showed that a sample of $\mathrm{O}$ chromosomes derived from a natural population revealed substantial variation in their modifier effect upon the expression of $B a$, and that this modifier variability could be explained in terms of polygenic factors located on the $\mathrm{O}$ chromosome (Alvarez et al., 1980, 1981). In this paper our first goal is to quantify the amount of genetic variation in modifier effect in natural populations and so extend our earlier observations to a larger sample of chromosomes. Secondly, we investigate the genetic architecture of this modifier system in which both the major locus and minor modifier loci are located on the same chromosome. It is necessary to point out that the polygenic basis of this modifier system does not necessarily prevent its genetic disection. Thus, the occurrence of a continuous distribution for a quantitative trait does not necessarily imply that 
this trait is governed by a large number of genes, as has been emphasized by Thoday and Thompson (1976) and Thompson (1975b, 1976). In addition, biometrical techniques for locating and mapping polygenes such as those of Thoday $(1961,1979)$ have been successfully used in several instances (Davies, 1971; Thompson, 1975a; Shrimpton and Robertson, $1988 a, b)$. In the present paper, we use these biometrical methods to analyze the genetic architecture of the modifier system that affects the $B a$ mutant and is located on the $\mathrm{O}$ chromosome of D. subobscura.

\section{MATERIALS AND METHODS}

\section{Marker strains}

Two marker stocks of $D$. subobscura, ch-cu and $V a / B a$, were used in the experiments. The $c h-c u$ strain is homozygous for two recessive morphological mutants, cherry ( $c h$, bright red eye colour) and curled ( $c u$, curled wings), both located on the O chromosome (Koske and Maynard-Smith, 1954; Loukas et al., 1979; Böhm et al., 1987). This stock is also homozygous for the $\mathrm{O}_{3+4}$ chromosomal arrangement.

The $V a / B a$ stock is a balanced lethal strain for the $\mathrm{O}$ chromosome of D. subobscura (Sperlich et $a l ., 1977)$. The $V a / B a$ strain carries two dominant morphological mutants located on chromosome $\mathrm{O}$, Varicose ( $V a$, wing venation mutant) and Bare $(B a$, bristles mutant), both lethal in homozygous condition (Koske and Maynard-Smith, 1954; Sperlich et al., 1977). The $V a$ chromosome carries the ch and $c u$ mutants and an inversion complex to suppress recombination. The $B a$ chromosome has the standard chromosomal arrangement $\left(\mathrm{O}_{\mathrm{ST}}\right)$ and is wild-type for the $c h$ and $c u$ loci.

\section{Measurement of modifier effect of $O$ chromosomes}

Bare $(B a)$ is a mutant that reduces variably the number of macrochaetae and is located on the $\mathrm{O}$ chromosome $(54.7 \mathrm{cM})$ of D. subobscura (Koske and Maynard-Smith, 1954; Loukas et al., 1979). The effect of a particular $\mathrm{O}$ chromosome on the phenotypic expression of $B a$ was measured by crossing a male heterozygous for that $\mathrm{O}$ chromosome and a $V a$ chromosome, with $V a / B a$ females (see fig. 1). In the offspring of this cross the effect of the $\mathrm{O}$ chromosome on $\mathrm{Ba}$ expressivity was observed by comparing the phenotype of the $+/ B a$ individuals relative to the $V a / B a$ genotype, which was used as a control. Given that both $+/ B a$ and a) Isogenic Iines

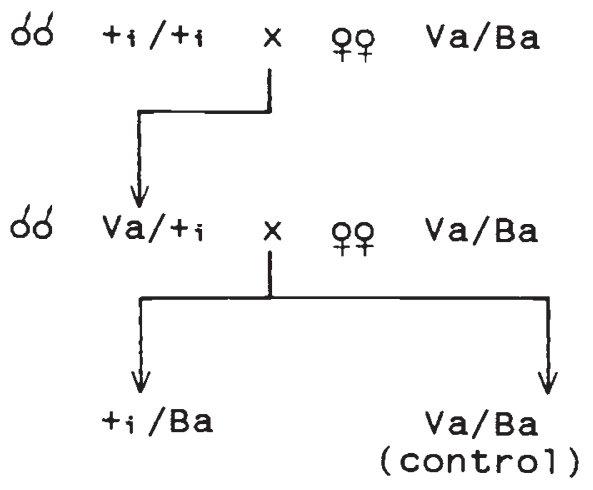

b) Natural population

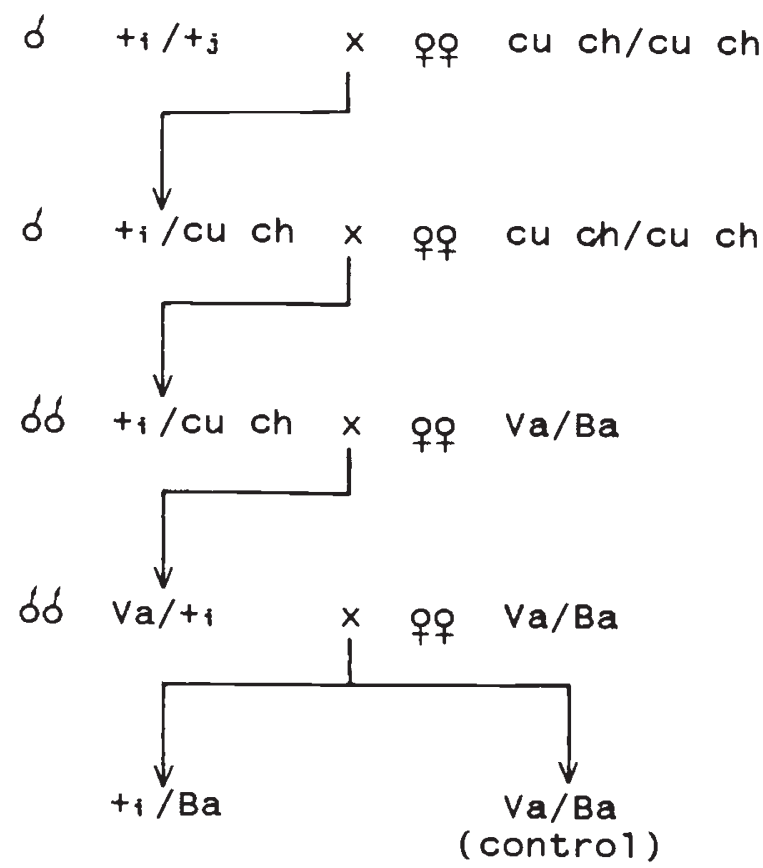

Figure 1 Crosses for measuring modifier effect of $\mathrm{O}$ chromosomes extracted from (a) isogenic lines, and (b) natural population.

$V a / B a$ genotypes have in common the $B a$ chromosome the modifier effect of the wild-type chromosome was measured by the difference in mean number of bristles between $+/ B a$ and $V a / B a$ individuals ( $D$ value). In the experiments, 12 bristles per individual (four scutellars, four dorso- 
centrals, two supra-alars and two post-alars) of 30 $+/ \mathrm{Ba}$ and $30 \mathrm{Va} / \mathrm{Ba}$ flies were scored in each one of 3-4 replicates in order to estimate the modifier effect of each chromosome.

\section{Modifier variability in natural populations}

Two sets of $\mathrm{O}$ chromosomes of different origin have been studied: chromosomes extracted either from isogenic lines or from a natural population. The isogenic lines were obtained by Zapata et al. (1986) from wild males collected from a natural population, El Pedroso (Santiago de Compostela, NW of Spain), to found experimental populations of $D$. subobscura. In order to quantify the chromosomal modifier effect, wild-type males from each isogenic line were mated separately to $\mathrm{Va} / \mathrm{Ba}$ females (see fig. 1a). Then, $V a / t_{i}$ males of the offspring were crossed with $V a / B a$ females and bristles of $+_{\mathrm{i}} / \mathrm{Ba}$ and $\mathrm{Va} / \mathrm{Ba}$ (control genotype) individuals of the progeny were counted to measure the chromosome modifier effect as usual.

In order to measure the modifier effect of $\mathrm{O}$ chromosomes directly derived from a natural population, wild males were trapped on the south slopes of El Pedroso mountain, $3 \mathrm{~km}$ from Santiago de Compostela (NW of Spain). The wild male flies were individually mated to $\mathrm{cuch} / \mathrm{cu}$ ch females and a single $F_{1}$ phenotypically wild male $\left(+_{i} / c u c h\right.$ heterozygote) was backcrossed with $\mathrm{cu} c h / c u c h$ females (see fig. 1b). The identification of the chromosomal arrangements of the wild O chromosomes was performed in third-instar larvae obtained from the progeny of the backcrosses. The squash technique and staining with lactoacetic orcein (lactic acid: acetic orcein, $3: 1$ ) was used to observe the polytene chromosomes of salivary glands of larvae. Eight larvae of the progeny of every backcross were analyzed so that the probability of not detecting the wild $\mathrm{O}$ chromosome equals $0 \cdot 004$. When the arrangement of each wild chromosome had been established quantification of the modifier effects of these chromosomes was carried out. Only chromosomes with the most frequent arrangements $\left(\mathrm{O}_{\mathrm{ST}}\right.$ and $\mathrm{O}_{3+4+7}$, see Fontdevila et al., 1983) were used. The $+/$ cu ch males carrying a wild $\mathrm{O}$ chromosome with either $\mathrm{O}_{\mathrm{ST}}$ or $\mathrm{O}_{3+4+7}$ arrangements were crossed with $\mathrm{Va} / \mathrm{Ba}$ females. In the progeny of this last cross the chromosome modifier effect was measured as usual (see fig. 1b).

\section{Locating modifier effects on 0 chromosome}

Location of polygenic loci responsible for modifier effects was attempted using Thoday's method
(Thoday, 1961, 1979). In the present paper the terms "polygenic locus" (Thompson and Thoday, 1974), "effective factor" (Mather and Jinks, 1971) and "factor" (Shrimpton and Robertson, 1988a) are used as synonymous to refer to a located polygenic effect corresponding to a locus composed of one or more closely linked genes. Accordingly to Thoday's method a heterozygote between a tester chromosome with recessive visible markers and low score and a tested chromosome of high score must be obtained. Then, cross-over chromosomes corresponding to recombinant marker classes are isolated and detection of heterogeneity inside each marker recombinant class is attempted. The number of homogeneous groups contained in a recombinant class indicates the number of polygenic loci or effective factors located between the corresponding markers.

In D. subobscura the power of Thoday's method is limited by the number of suitable markers given that in this species there are few available morphological mutants. We used the ch$c u$ strain as a tester stock marked with two recessive mutants since this stock presents a low modifier effect (Alvarez et al., 1980). The chromosome tested was the $\mathrm{O}$ chromosome of the 220 line $\left(\mathrm{O}_{220}\right)$ which was the chromosome with the highest modifier score. This chromosome carries the $\mathrm{O}_{\mathrm{ST}}$ chromosomal arrangement. The location of morphological markers on the $\mathrm{O}$ chromosome $(\mathrm{cu}$, $52.6 \mathrm{cM}$; ch, $98.2 \mathrm{cM}$; Loukas et al., 1979; see also Böhm et al., 1987) allows us to divide the $\mathrm{O}_{220}$ chromosome into three chromosomal regions $(0 \cdot 0$ $52 \cdot 6 \mathrm{cM} ; 52 \cdot 6-98 \cdot 2 \mathrm{cM}$ and $98 \cdot 2$-approximately $230 \mathrm{cM}$, see fig. 2). The occurrence of the $\mathrm{O}_{3+4}$ inversion in the $c h-c u$ strain prevents recombination in the third section given the breakpoint of this arrangement is located at $105 \cdot 3 \mathrm{cM}$, mapping at a distance of $7 \cdot 1 \mathrm{cM}$ from the $\mathrm{ch}$ locus. Therefore, recombination will be practically blocked all along the third chromosomal region and, as explained later, we will take advantage of this fact.

In the progeny of the heterozygotes between the tester and the tested chromosome (fig. 2) we picked up $\mathrm{Va} / \mathrm{cu}+, \mathrm{Va} /++$ and $\mathrm{Va} / \mathrm{cu} \mathrm{ch}$ individuals (41, 31 and 25 males, respectively) and they were progeny tested for modifier effects. Thus, these males were individually crossed to $\mathrm{Va} / \mathrm{Ba}$ females and bristles for $+/ B a$ and $V a / B a$ individuals among the offspring were scored. We paid special attention to the recombinant marker class $(\mathrm{Va} / \mathrm{cu}+)$ given that preliminary experiments showed that a larger part of the O chromosome modifier effect seems to be located precisely in this chromosomal region between $c u$ and $c h$. 
MALE

$0_{220}$
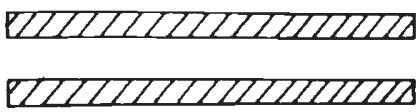

$\mathrm{O}_{220}$
FEMALE

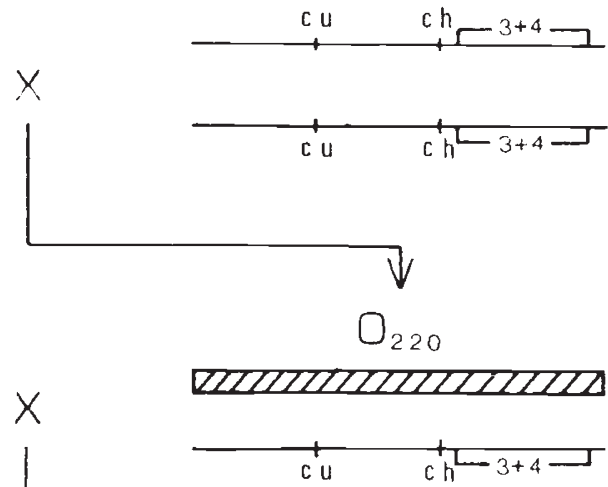

$V_{a} / B_{a}$

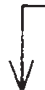

$\sqrt{ }$

$\mathrm{Va} / \mathrm{Cu}+$

$\mathrm{Va} / \mathrm{cu} \mathrm{ch}$

$\mathrm{Va} /++$

Figure 2 Crosses performed for location of modifier effects on the $\mathrm{O}$ chromosome.

The progeny tests were repeated during five successive generations for the 41 recombinant chromosomes isolated. Repeated progeny-tests of the recombinant chromosomes decreases background variation and allow us a more precise measurement of the chromosome modifier effect.

On the other hand, the $\mathrm{Va} / \mathrm{cu}$ ch and $\mathrm{Va} /++$ parental classes were used to investigate the first region of the $\mathrm{O}$ chromosome. Given that the recombination in the third region is blocked by the $\mathrm{O}_{3+4}$ inversion the occurrence of heterogeneity for modifier scores at the parental classes would be evidence for recombination inside the first region of the chromosome, ignoring double crossing-over. The two parental classes $\mathrm{Va} / \mathrm{cu} \mathrm{ch}$ and $\mathrm{Va} /++$ have to produce two complementary mirror images. Progeny-testing was also carried out for these parental classes but only during three successive generations (three retests).

\section{Statistical procedures}

Statistical analyses of results were performed by means of the SPSS statistical package. Some of the statistical tests used, as for example the analysis of variance, assume data normally distributed which could not be the case with a meristic trait as number of bristles. In order to circumvent this problem, averages of number of bristles were always used in the computations for statistical testing given that distributions of means will approach the normal distribution according to the central limit theorem (Sokal and Rohlf, 1981). In order to check this possibility the distributions of mean numbers of bristles of $\mathrm{Va} / \mathrm{Ba}$ flies (averages over 30 individuals) in the experiment to measure modifier variability were analyzed by means of the Kolmogorov-Smirnov goodness of fit test to normal distribution (Sokal and Rohlf, 1981). The Kolmogorov-Smirnov statistic ( $d_{\max }$ statistic) is 0.05 $(N=201, P>0.05)$ for the distribution of mean numbers of bristles of $\mathrm{Va} / \mathrm{Ba}$ flies in the experiment with isogenic lines and $0.08(N=133, P>$ $0.05)$ in the experiment with chromosomes from the natural population. Therefore, normality for the distributions of mean numbers of bristles can be assumed.

\section{Culture conditions}

All the experiments were carried out under strictly controlled environmental conditions, at a constant 
temperature of $19^{\circ} \mathrm{C}$ and $60-70$ per cent of relative humidity. The culture medium used is described by David (1959).

\section{RESULTS}

\section{Modifier variability}

A sample of $86 \mathrm{O}$ chromosomes coming from a natural population of $D$. subobscura (El Pedroso, Spain) has been assayed for modifier effect upon the expression of $B a$ mutant. From this sample 52 chromosomes were obtained from a collection of isogenic lines while the remaining 34 chromosomes were directly extracted from the natural population. The distributions of chromosome modifier effects for $\mathrm{O}_{\mathrm{ST}}$ and $\mathrm{O}_{3+4+7}$ arrangements are given in fig. 3 (descriptive statistics for these distributions are shown in table 1 ). The $\mathrm{O}$ chromosomes present a wide range of modifier effect. Some chromosomes present a high modifier score with mean $D$ values

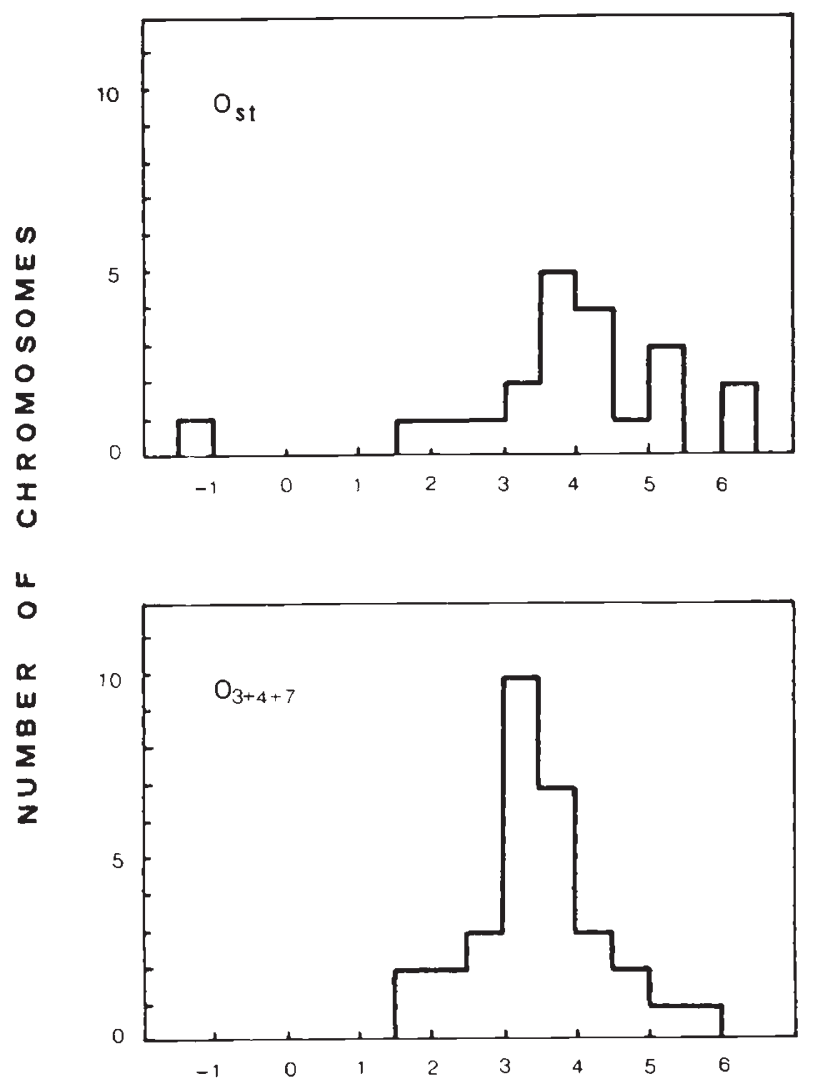

between five and seven. This means that the chromosome effects upon $B a$ mutant measured by the difference in the mean number of bristles between $+/ B a$ individuals and the control genotype $(\mathrm{Va} / \mathrm{Ba})$ is between five and seven bristles out of a total of 12 bristles scored per individual. Therefore, some chromosomes reduce the expressivity of the $B a$ mutant attenuating its dominance and producing $+/ B a$ heterozygous individuals with a phenotype very similar to that of the wild-type. On the other hand, other chromosomes show an opposite effect producing negative mean $\mathrm{D}$ values. In these cases, the $\mathrm{O}$ chromosome increases the expression of the $B a$ mutant in heterozygous condition. The analyses of variance of modifier effect of chromosomes carried out separately for each chromosomal arrangement show that $\mathrm{O}$ chromosomes isolated either from isogenic lines or from the natural population present an important degree of modifier variability in the El Pedroso natural population (table 2). Modifier
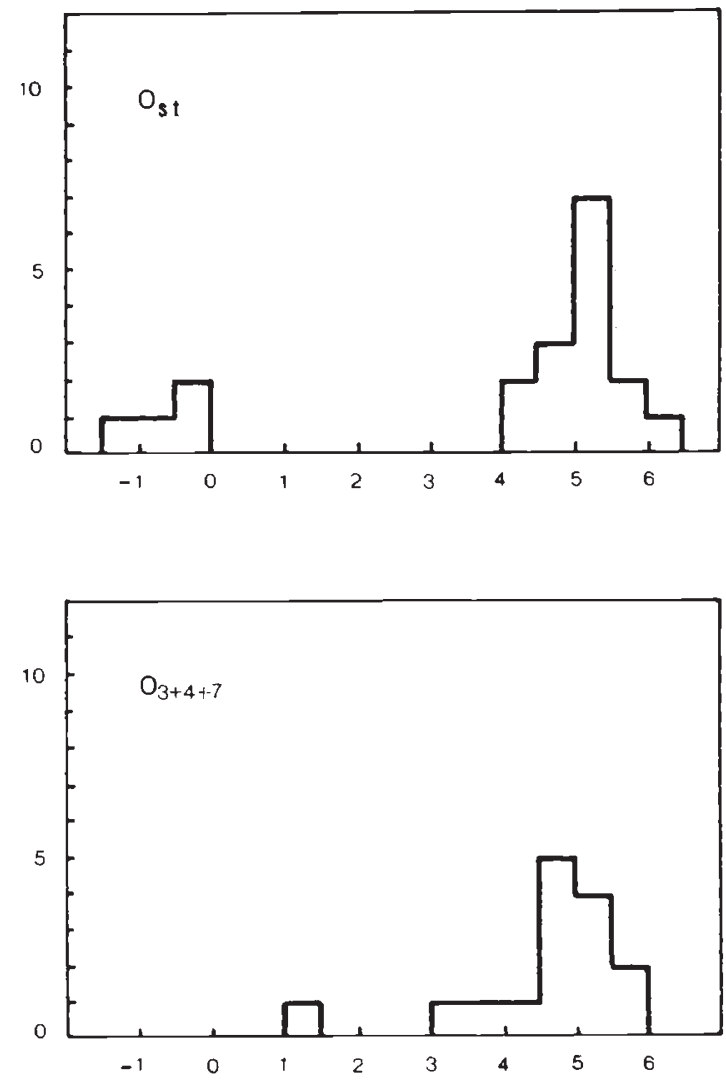

MODIFIER EFFECT

Figure 3 Distributions of modifier effect (mean D value) of $\mathrm{O}_{\mathrm{ST}}$ and $\mathrm{O}_{3+4+7}$ chromosomes extracted from isogenic lines (left) and natural population (right). 
Table 1 Statistics corresponding to the distributions of modifier effect (mean D values) of $\mathrm{O}_{\mathrm{ST}}$ and $\mathrm{O}_{3+4+7}$ chromosomal arrangements

Chromosomes $\mathrm{O}$ from isogenic lines

\begin{tabular}{|c|c|c|c|c|c|c|c|c|}
\hline $\begin{array}{l}\text { Chromosomal } \\
\text { arrangement }\end{array}$ & Mean $\pm \mathrm{SE}$ & Variance & $\begin{array}{l}\text { Goodness } \\
\text { of fit } \neq\end{array}$ & $N$ & Mean $\pm \mathrm{SE}$ & Variance & $\begin{array}{l}\text { Goodness } \\
\text { of fit }\end{array}$ & $N$ \\
\hline $\mathrm{O}_{\mathrm{ST}}$ & $3 \cdot 80 \pm 0 \cdot 35$ & $2 \cdot 56$ & $0 \cdot 20^{*}$ & 21 & $3.94 \pm 0.58$ & $6 \cdot 32$ & $0 \cdot 33^{* *}$ & 19 \\
\hline
\end{tabular}

$* P<0.05$. ** $P<0.01$. $\dagger$ Close to $P<0.05$. $\ddagger$ Kolmogorov-Smirnov statistic.

Table 2 Analyses of variance of modifier effect ( $D$ value) of $\mathrm{O}_{\mathrm{ST}}$ and $\mathrm{O}_{3+4+7}$ chromosomes

\begin{tabular}{|c|c|c|c|c|}
\hline Source of variation & $\mathrm{df}$ & SS & MS & $F$ \\
\hline \multicolumn{5}{|l|}{$\begin{array}{l}\text { Among } \mathrm{O}_{\mathrm{ST}} \text { chromo- } \\
\text { somes from }\end{array}$} \\
\hline isogenic lines & 20 & $202 \cdot 61$ & $10 \cdot 13$ & $16 \cdot 34^{* * *}$ \\
\hline Within & 61 & $37 \cdot 67$ & 0.62 & \\
\hline Total & 81 & $240 \cdot 28$ & & \\
\hline \multicolumn{5}{|c|}{$\begin{array}{l}\text { Among } \mathrm{O}_{3+4+7} \text { chromo- } \\
\text { somes from }\end{array}$} \\
\hline isogenic lines & 30 & $92 \cdot 86$ & $3 \cdot 10$ & $5 \cdot 74^{* * *}$ \\
\hline Within & 88 & $47 \cdot 38$ & 0.54 & \\
\hline Total & 118 & $140 \cdot 24$ & & \\
\hline \multicolumn{5}{|c|}{$\begin{array}{l}\text { Among } \mathrm{O}_{\mathrm{ST}} \text { chromo- } \\
\text { somes from the }\end{array}$} \\
\hline natural population & 18 & $453 \cdot 90$ & $25 \cdot 22$ & $76 \cdot 42^{* * *}$ \\
\hline Within & 56 & $18 \cdot 53$ & 0.33 & \\
\hline Total & 74 & $472 \cdot 43$ & & \\
\hline \multicolumn{5}{|c|}{$\begin{array}{l}\text { Among } \mathrm{O}_{3+4+7} \text { chromo- } \\
\text { somes from the }\end{array}$} \\
\hline natural population & 14 & $65 \cdot 60$ & $4 \cdot 69$ & $11 \cdot 73^{* * *}$ \\
\hline Within & 43 & $17 \cdot 17$ & 0.40 & \\
\hline Total & 57 & $82 \cdot 77$ & & \\
\hline
\end{tabular}

*** $P<0.001$.

variability is higher in chromosomes directly coming from the natural population than in chromosomes extracted from isogenic lines (the variances of distributions of mean $D$ values are 6.32 and $1 \cdot 18$ for $\mathrm{O}_{\mathrm{ST}}$ and $\mathrm{O}_{3+4+7}$ chromosomes from the natural population in relation to 2.56 and 0.84 for the same arrangements in chromosomes coming from isogenic lines). It is necessary to consider that during the isogenization process those chromosomes bearing lethal and other deleterious mutations are lost. Therefore, genetic variability is erased in a set of isogenic lines and it could affect the modifier variation.

There are some differences in the distribution of modifier effect between the two chromosomal arrangements, $\mathrm{O}_{\mathrm{ST}}$ and $\mathrm{O}_{3+4+7}$ (fig. 3 , table 1). The distributions of mean $\mathrm{D}$ values of chromosomes present similar averages for $\mathrm{O}_{\mathrm{ST}}$ and $\mathrm{O}_{3+4+7}$, but these two arrangements show different levels of modifier variability. While the distribution of modifier effect does not depart significantly from normality in the $\mathrm{O}_{3+4+7}$ chromosomes, the distribution of $\mathrm{O}_{\mathrm{ST}}$ chromosomes clearly deviates from normality and presents a certain trend to bimodality. Thus, the variance of mean modifier values of chromosomes is clearly higher in the $\mathrm{O}_{\mathrm{ST}}$ chromosomes than in $\mathrm{O}_{3+4+7}$ ones, both in chromosomes from isogenic lines $(2.56$ vs. 0.84$)$ and in chromosomes extracted from the natural population $(6 \cdot 32$ vs. 1.18). Analyses of components of variance of modifier effect logically show the same trend (table 3 ). The variances associated to $\mathrm{O}_{\mathrm{ST}}$ chromosomes

Table 3 Components of variance of modifier effect ( $D$ value) for $\mathrm{O}_{\mathrm{ST}}$ and $\mathrm{O}_{3+4+7}$ chromosomes

\begin{tabular}{|c|c|c|c|c|c|c|}
\hline \multirow{2}{*}{$\begin{array}{l}\text { Chromosomal } \\
\text { arrangement }\end{array}$} & \multicolumn{3}{|c|}{ Isogenic lines } & \multicolumn{3}{|c|}{ Natural population } \\
\hline & $\mathrm{S}_{\mathrm{T}}^{2}$ & $\mathrm{~S}_{\mathrm{G}}^{2}$ & $\mathrm{~S}_{\mathrm{R}}^{2}$ & $\mathrm{~S}_{\mathrm{r}}^{2}$ & $\mathrm{~S}_{\mathrm{G}}^{2}$ & $\mathrm{~S}_{\mathrm{R}}^{2}$ \\
\hline $\mathrm{O}_{\mathrm{ST}}$ & $3 \cdot 06$ & $2 \cdot 44$ & 0.62 & $6 \cdot 63$ & $6 \cdot 30$ & $0 \cdot 33$ \\
\hline $\mathrm{O}_{3+4+7}$ & $1 \cdot 21$ & 0.67 & 0.54 & $1 \cdot 51$ & $1 \cdot 11$ & 0.40 \\
\hline
\end{tabular}

The total variance is $\mathrm{S}_{\mathrm{T}}^{2} ; \mathrm{S}_{\mathrm{G}}^{2}$ is the genetic variance ascribable to the chromsome $\mathrm{O}$ itself; $\mathrm{S}_{\mathrm{R}}^{2}$ is the variance due to environment, sampling, and residual genotype.

are clearly higher than those corresponding to the $\mathrm{O}_{3+4+7}$ arrangement (3.06 vs. 1.21 in isogenic lines, and 6.63 vs. 1.51 in chromosomes from the natural population). Partitioning the total variance in two components corresponding to the chromosome $\mathrm{O}$ itself and to the environment, sampling and background genotype, the results demonstrate that the genetic variance ascribable to chromosome $\mathrm{O}$ itself is responsible for the higher variance of modifier effect observed in the $\mathrm{O}_{\mathrm{ST}}$ arrangement. While the residual variance is practically equal in the two arrangements, the genetic variance is 2.44 in the $\mathrm{O}_{\mathrm{ST}}$ chromosomes and only 0.67 in the $\mathrm{O}_{3+4+7}$ ones for the isogenic lines, and $6 \cdot 30$ vs. $1 \cdot 11$ for the chromosomes directly extracted from the natural population. 


\section{Location of modifier effects on O chromosome}

In order to identify polygenic loci contributing to modifier variation, recombination between a chromosome of high modifier effect $\left(\mathrm{O}_{220}\right)$ and the marker chromosome of the ch-cu strain of low modifier score was studied by means of progeny tests. A total of $41 \mathrm{cu}+$ recombinant chromosomes were assayed for modifier effect in five successive generations in order to improve the power of detection since preliminary experiments had showed that most modifier effect attributed to the $\mathrm{O}$ chromosome is located between the $c u$ and $c h$ markers (second chromosomal section, 52.6-
$98.2 \mathrm{cM})$. In addition, 56 parental chromosomes, $25 \mathrm{cu} c h$ and $31++$, were also studied. Chromosomes of the parental classes were studied to investigate the first chromosomal section $(0 \cdot 0$ $52.6 \mathrm{cM})$. This was possible because the $\mathrm{O}_{3+4}$ inversion of the $c h-c u$ stock prevents recombination at the third section of the chromosome in the females heterozygous for $\mathrm{O}_{220}$ and $c h-c u$ chromosomes. Consequently, parental marker classes ( $c u$ ch and ++ ) will consist of both non-recombinant chromosomes and chromosomes recombined at section 1 (discounting double cross-overs). Fig. 4 shows the histograms corresponding to the distributions of the chromosome modifier effects for each

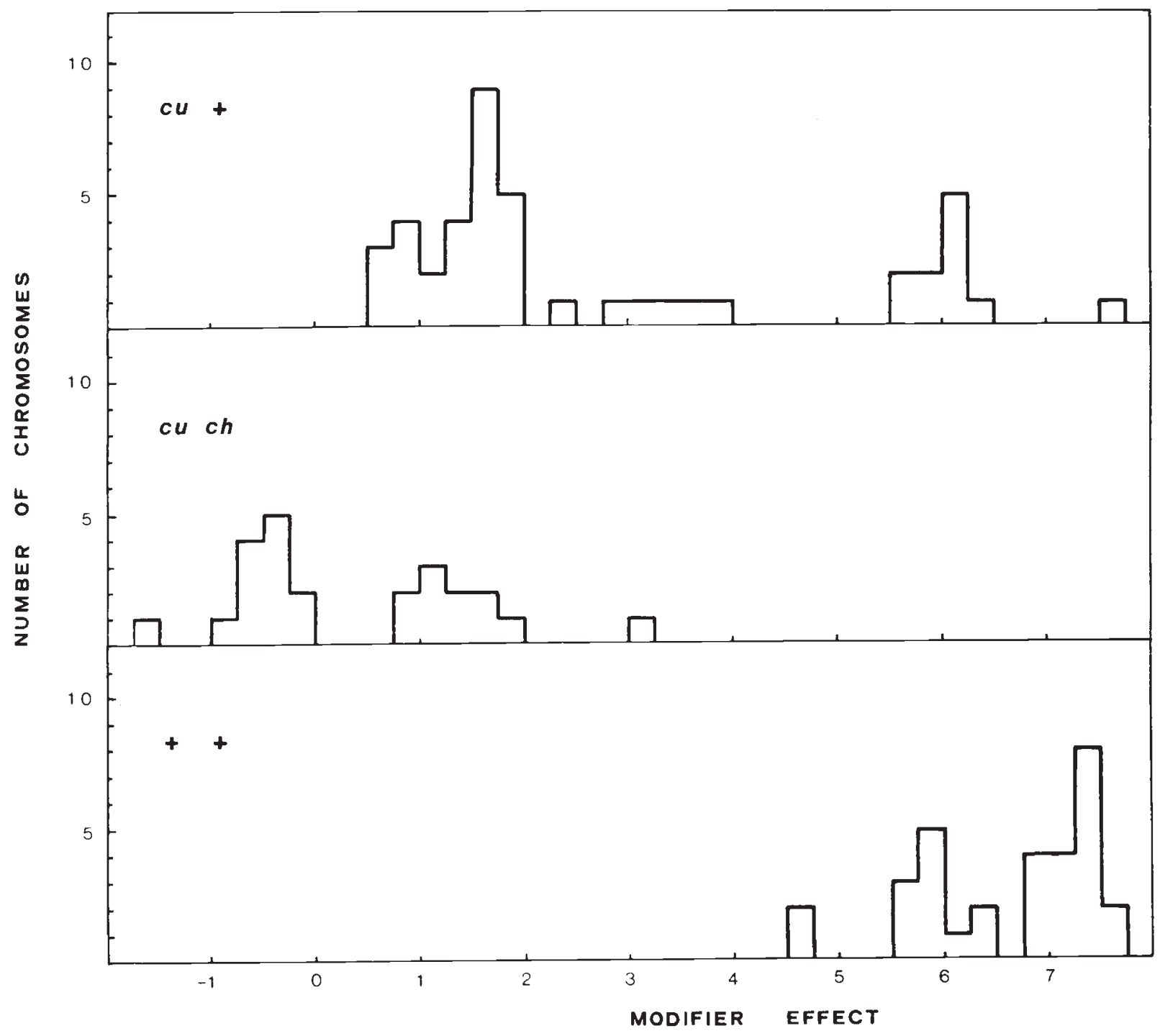

Figure 4 Distribution of modifier effect (mean D value) of $c u+, c u c h$ and ++ chromosomes. 
Table 4 Chromosome groups of homogeneous modifier effect inside recombinant and parental marker classes

\begin{tabular}{|c|c|c|c|c|c|}
\hline $\begin{array}{l}\text { Marker } \\
\text { class }\end{array}$ & $\begin{array}{l}\text { Number of } \\
\text { chromosomes }\end{array}$ & $\begin{array}{l}\text { Mean modifier } \\
\text { effect }\end{array}$ & $\begin{array}{l}\text { Difference in mean } \\
\text { modifier effect }\end{array}$ & Location & $\begin{array}{l}\text { Map } \\
\text { position } \\
(\mathrm{cM})\end{array}$ \\
\hline \multirow[t]{4}{*}{$c u+$} & 9 & 0.85 & & & \\
\hline & 18 & 1.66 & 0.81 & $33 / 42$ & $88 \cdot 4$ \\
\hline & 5 & $3 \cdot 44$ & $1 \cdot 78$ & $15 / 42$ & $68 \cdot 9$ \\
\hline & 10 & $6 \cdot 00$ & $2 \cdot 56$ & $10 / 42$ & $63 \cdot 5$ \\
\hline \multirow[t]{2}{*}{ cuch } & 12 & $-0 \cdot 50$ & & & \\
\hline & 11 & $1 \cdot 34$ & $1 \cdot 84$ & $11 / 23$ & $4 \cdot 8$ \\
\hline \multirow[t]{2}{*}{++} & 11 & $5 \cdot 94$ & & & \\
\hline & 18 & $7 \cdot 25$ & $1 \cdot 31$ & $11 / 29$ & $14 \cdot 7$ \\
\hline
\end{tabular}

marker class (see also table 4). The chromosome modifier effects are the average of modifier scores (D values) of each chromosome in the different progeny tests (five replicates for $c u+$ chromosomes and three replicates for $c u c h$ and ++ chromosomes). The chromosomes of the recombinant marker class are clearly heterogeneous, and although there is some misclassification the $c u+$ recombinants fall into four main classes (fig. 4). The Student-Newman-Keuls test (Sokal and Rohlf, 1981) for chromosome pairs shows that these four chromosome groups are homogeneous sets of chromosomes since this test does not detect statistically significant differences among chromosomes inside these groups. From these results it is concluded that a minimum number of three modifier factors must be located between $c u$ and $c h$ markers. The histograms corresponding to the two parental marker classes show in both cases two groups of chromosomes separated by a clear gap between them. The Student-Newman-Keuls test detects statistically significant differences between the two chromosome groups of the $c u c h$ class but not between the two groups of ++ chromosomes. However, given that the two parental classes must produce mirror images the occurrence of two different chromosome groups is assumed. According to this result at least one modifier factor must be present in the first section of the $\mathrm{O}$ chromosome $(0 \cdot 0-52 \cdot 6 \mathrm{cM})$.

The effects of the modifier factors are estimated from differences in mean scores of the homogeneous groups of chromosomes (table 4). The modifier effects corresponding to the three factors located inside the second chromosomal region are $0.81,1.78$ and 2.56 . The modifier effect corresponding to the factor of the first chromosomal region is estimated to be 1.84 or 1.31 according to the parental class considered ( $c u c h$ or ++ , respectively). The modifier effect of this factor can also be estimated by comparing $\mathrm{cu}+$ and ++ marker classes. The difference in mean scores between the highest chromosome group of the $\mathrm{cu}+$ class and the non recombinant chromosomes of the ++ class estimates this modifier effect as $1 \cdot 25$, a value very close to those previously obtained (the average of the three estimates is $1 \cdot 47 \pm 0 \cdot 19$ ). In a similar way, the difference between the non recombinant $\mathrm{cu}$ ch chromosomes and the lowest chromosome group of the $c u+$ class produce an estimate of the modifier effect situated in the third chromosomal section. This moddifier effect is estimated to be $1 \cdot 35$, and according to the experimental design used it is not possible to know how many factors are responsible for this effect. Modifier effects of the polygenic loci can be expressed in units of phenotypic standard deviations. The weighted average of the standard deviations of $\mathrm{D}$ values corresponding to the three marker classes in the experiments of polygenic location is 0.56 . Therefore, modifier scores in standard deviation units are $4 \cdot 57,3 \cdot 18$ and 1.45 for the modifier factors located in the second chromosomal region and 2.63 for the factor of the first section.

The detected modifier factors can be approximately located on the genetic map of the $O$ chromosome. The rationale for mapping polygenic loci is very simple and is based on the observed frequencies corresponding to the homogeneous chromosome groups (see table 4). Fig. 5 shows the approximate location of the four polygenic factors responsible for modifier effect on the $\mathrm{O}$ chromosome.

\section{DISCUSSION}

The results presented in this paper clearly demonstrate that there is considerable genetic variation 


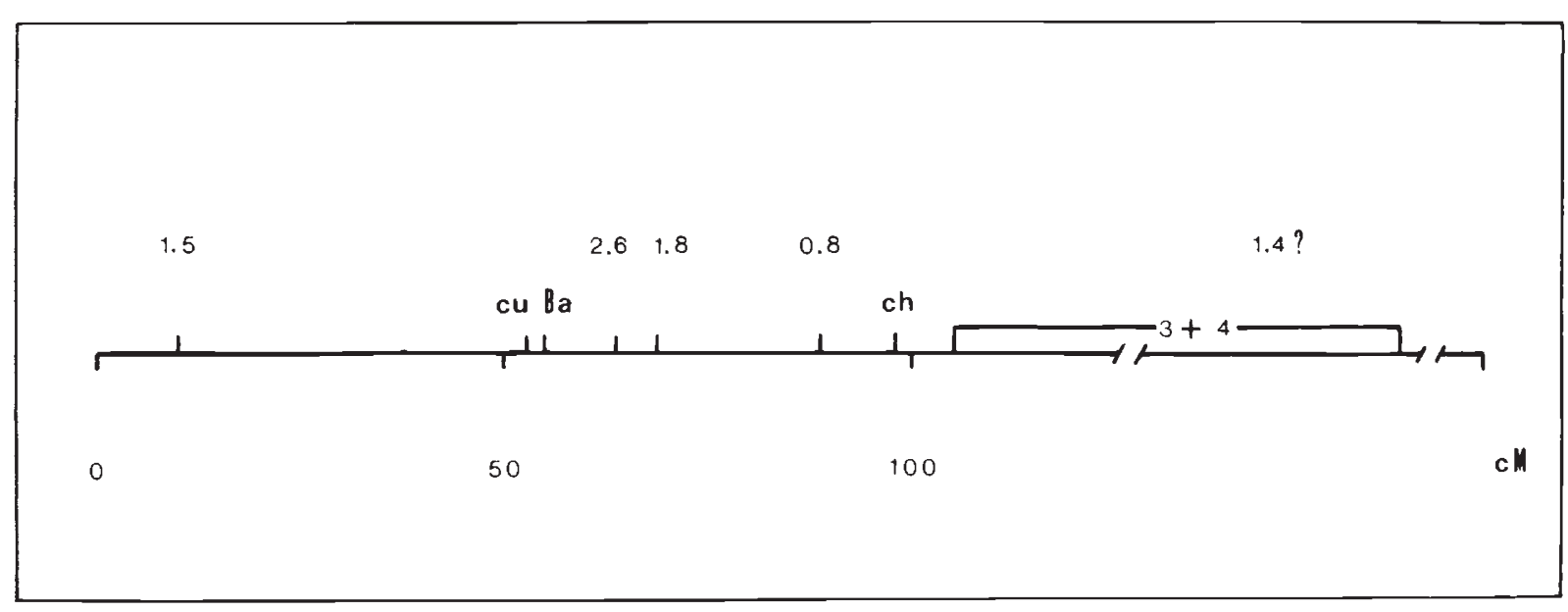

Figure 5 A map showing the distribution of modifier effect differences between $\mathrm{O}_{220}$ and marker chromosomes.

among $\mathrm{O}$ chromosomes derived from the $\mathrm{El}$ Pedroso natural population of $D$. subobscura in their modifying effect on the expression of the Bare mutant. This modifier variability is observed in $\mathrm{O}$ chromosomes extracted either from isogenic lines or from wild males captured from the natural population (fig. 3). This modifier variability affects the dominance relationships between + and $\mathrm{Ba}$ alleles in an important way. Thus, the mean modifier scores (mean D values) of chromosomes from the natural population range from -1 to about $6-7$. This means that some $\mathrm{O}$ chromosomes produce a mean increment of $6-7$ bristles in $+/ B a$ heterozygotes with respect to $V a / B a$ individuals (control genotype), so that these $+/ B a$ individuals present a phenotype very close to the wild-type. In contrast, other $\mathrm{O}$ chromosomes provoke a slight reduction of the mean number of bristles in $+/ B a$ heterozygotes and so increase the dominance of $B a$. In general terms, the results reported here are in agreement with the studies on other types of modifiers. Thus, significant levels of genetic variation for enzyme activity modifiers in natural populations of $D$. melanogaster have been reported for a large number of enzymes (Laurie-Ahlberg et al., 1982; Wilton et al., 1982; Tepper et al., 1982, 1984; Geer and Laurie-Ahlberg, 1984). Hence, the analyses of a variety of modifier systems in natural populations of Drosophila show the existence of a high degree of naturally occurring modifier variability.

The genetic architecture underlying the modifier variation associated with the $\mathrm{O}$ chromosome has been investigated using biometrical methods for locating polygenes (Thoday, 1961, 1979). A single O chromosome of high modifier score was analyzed by means of a tester chromosome of the $c h-c u$ strain. The difference in modifier score ( $D$ values) between these two chromosomes is eight bristles. The results obtained from this analysis show that all three regions of the $\mathrm{O}$ chromosome present some modifier effect. However, the distribution of modifier effect is not uniform along the $\mathrm{O}$ chromosome. Most modifier effect (about 65 per cent of the total effect) is located on the second section of chromosome, while each one of the two other sections present a modifier effect of only about $17-18$ per cent. In the second chromosomal region three polygenic factors have been detected and mapped (see fig. 5 ). The estimates of modifier effect of these three factors are $2.56,1.78$ and 0.81 (or, in terms of phenotypic strandard deviation units, values are $4 \cdot 57,3 \cdot 18$ and 1.45 respectively). In the first section, one factor of $1.47(2.63$ phenotypic standard deviations) is detected and in the third chromosomal section a modifier effect of $1.35(2.41$ standard deviations), probably corresponding to a single factor, is observed. Therefore, a minimum number of five polygenic loci on the $\mathrm{O}$ chromosome are involved in the modifier effect. These results show that the modifier variation associated with the $\mathrm{O}$ chromosome can be explained in terms of a limited number of modifier factors located on specific regions of this chromosome.

In relation to the estimated size of the modifier factors affecting the expression of $B a$ mutant is necessary to point out that these factors present a high estimated size in comparison with other studies. Thus, in an extensive investigation of the number of sternopleural bristles of $D$. melanogaster, Shrimpton and Robertson (1988b) 
were capable of detecting polygenic factors with effects as low as 0.3 phenotypic standard deviations being the modal number of 0.6 standard deviations. The difference in the estimates between our study and that of Shrimpton and Robertson is probably due to the precision of the techniques of detection. Firstly, the scarcity of morphological markers available in $D$. subobscura does not permit division of the $\mathrm{O}$ chromosome into short sections. Secondly, the number of modifier factors detected is largely determined by the amount of experimental effort carried out. The more recombinant lines collected, the more factors separated, and the more flies scored per line the greater the precision in the measurement of modifier effects of each chromosome. In contrast with the investigations of Shrimpton and Robertson our study deals with a quantitative trait which must be measured as a difference between scores corresponding to individuals of different genotype and this requires more experimental work. All these factors result in a relatively low number of recombinant chromosomes analyzed in our experiments in comparison with those of Shrimpton and Robertson. As a consequence, we are probably under-estimating the number of polygenes responsible for the modifier variation and the detected polygenic loci could be effective factors composed of several closely linked polygenes rather than single modifier genes.

In connection with the distribution of modifier effect on the $\mathrm{O}$ chromosome, it is important to note that some indication of clustering of modifier factors around the locus $B a$ is observed (see fig. 5). Thus, the major locus and the two factors with the highest effect (about 54 per cent of the total modifier effect) are located in a chromosomal region of about $15 \mathrm{cM}$. It is a matter for speculation whether this is an accidental result or a reflection of some major feature of organization of the modifier system. In this sense, genetic structures, consisting of a major locus surrounded by a cluster of linked modifiers, are typical of mimicry supergenes in several species of butterflies (see Turner, 1977). These mimicry complexes are supergenes composed of a group of several closely linked loci that interact with one another to produce the mimetic phenotype. Theoretical studies of Charlesworth and Charlesworth (1976) have demonstrated that these supergenes could arise from a major mimicry locus and minor mutations occurring at modifier loci closely linked to the major locus. The critical point for this system to evolve is linkage because unlinked modifiers would be eliminated by natural selection. From this perspective, the cluster of modifier loci lying in the proximity of the $B a$ locus could be a genetic structure originating from an evolutionary process similar to that attributed to mimicry supergenes.

Finally, one aspect of our results that also deserves attention is the dependence of the amount of modifier variability on chromosomal arrangements of $\mathrm{O}$ chromosome. The two arrangements of the $\mathrm{O}$ chromosome frequently found in the sampled natural population, $\mathrm{O}_{\mathrm{ST}}$ and $\mathrm{O}_{3+4+7}$, present a clearcut difference in their modifier variability (fig. 3, table 3). The genetic variance of modifier effect ascribable to the $\mathrm{O}$ chromosome in $\mathrm{O}_{\mathrm{ST}}$ is more than three times that in $\mathrm{O}_{3+4+7}(2 \cdot 44$ vs. 0.67 for isogenic lines, and $6 \cdot 30$ vs. $1 \cdot 11$ for chromosomes extracted from the natural population). We believe that this result is probably related to the historical origin of inversions of the $\mathrm{O}$ chromosome. Taking into account the mechanism by which inversions are thought to arise it is valid to suppose that the amount of genetic variability must be higher in old arrangements than in new inversions (Krimbas and Loukas, 1980; Pinsker and Sperlich, 1981; Zapata et al., 1982; Prevosti et al., 1983). However, it is difficult to establish a specific hypothesis on this subject since $\mathrm{O}_{3+4+7}$ and $\mathrm{O}_{\mathrm{ST}}$ are complex chromosomal arrangements differing by three inversions and a controversy exists on phylogeny of the $\mathrm{O}_{3+4}$ arrangement (see Krimbas and Loukas, 1980, 1984; Zapata et al., 1982). Moreover, in order to formulate any specific phylogeny hypothesis it is necessary to know the distribution of modifier polygenes on the $\mathrm{O}$ chromosome given that modifiers could be scattered all over the $\mathrm{O}$ chromosome or they could be concentrated on one or more specific regions of the chromosome. The investigations presented in this paper on the distribution of modifier factors on the $\mathrm{O}$ chromosome have disclosed that the majority of the chromosome modifier effect ( 83 per cent of total effect) is located between the centromere and the ch marker. Only 17 per cent of the chromosome modifier effect is located apart from the ch locus in the chromosomal zone where the $\mathrm{O}_{3+4}$ arrangement occurs (see fig. 5 and Loukas et al., 1979). Consequently, more probably the different modifier variability between $\mathrm{O}_{\mathrm{ST}}$ and $\mathrm{O}_{3+4+7}$ is due to the $\mathrm{O}_{7}$ inversion. Though the boundaries of the $\mathrm{O}_{7}$ inversion are not exactly known (see Loukas et al., 1979) this inversion must include certain part of the chromosomal region situated between $c u$ and $c h$ markers, the region precisely where a great part of chromosome modifier effect is located (about 65 per cent of the total effect). On this basis, the $\mathrm{O}_{7}$ inversion would have a low modifier variability in relation to the $\mathrm{O}_{\mathrm{ST}}$ homologous arrange- 
ment which must be considered as the older arrangement for this chromosomal zone. This phylogenetic hypothesis would agree with those predictions based on other criteria as the geographic distribution, criterion of centrality and the analyses of chromosomal arrangements in closely related Drosophila species (see Krimbas and Loukas, 1984). In addition, this zone of the O chromosome supports more inversions in the $\mathrm{O}_{\mathrm{ST}}$ than in the $\mathrm{O}_{7}$ arrangement (Krimbas and Loukas, 1980), it being reasonable to assume that, of two alternative arrangements, the ancestral supports more new inversions than the derivative arrangement because of the length of time it has been in the gene pool (Olvera et al., 1979).

\section{REFERENCES}

Alvarez, G., ZAPATA, C. AND FONTDEvila, A. 1980. Modifier variability in a natural population of Drosophila subobscura. Genet. Acta biol. yugosl. 12, 81-89.

Alvarez, G. MARTINEZ, P. ZAPATA, C. SANTOS, M. AND FONTDEVILA, A. 1981. Genetic analysis of modifier variability in Drosophila subobscura. Experientia, 37, 1150-1151.

BÖHM, I., PINSKER, W. AND SPERLICH, D. 1987. Cytogenetic mapping of marker genes on the chromosome elements $C$ and $\mathrm{E}$ of Drosophila pseudoobscura and D. subobscura. Genetica, 75, 89-101.

CHARLESWORTH, D. AND CHARLESWORTH, B. 1976. Theoretical genetics of Batesian mimicry. II. Evolution of supergenes. J. Theor. Biol., 55, 305-324.

DAVID, J. 1959. Etude quantitative du développement de la Drosophile élevée en milieu axénique. Bull. biol. Fr. Belg., 93, 472-505.

DAVIES, R. W. 1971. The genetic relationship of two quantitative characters in Drosophila melanogaster. II. Location of the effects. Genetics, 69, 363-375.

FELDMAN, M. W. AND KRAKAUER, J. 1976. Genetic modification and modifier polymorphisms. In Karlin, S. and Nevo, E. (eds) Population Genetics and Ecology, Academic Press, Inc., London, pp. 547-583.

FonTdeVila, A. ZAPATA, C., Alvarez, G., SANCHEZ, L., MENDEZ, J. AND ENRIQUEZ, I. 1983. Genetic coadaptation in the chromosomal polymorphism of Drosophila subobscura. I. Seasonal changes of gametic disequilibrium in a natural population. Genetics, 105, 935-955.

FRASER, A. S. 1968. Specificity of modifiers of scute and extravert expression. Genetics, 60, 179

GeER, B. W. AND LAURie-AhlberG, c. C. 1984. Genetic variation in the dietary sucrose modulation of enzyme activities in Drosophila melanogaster. Genet. Res. Camb., 43, 307-321.

KOSKE, T. AND MAYNARD-SMITH, J. 1954. Genetics and cytology of Drosophila subobscura. X. The fifth linkage group. J. Genet., 52, 521-541.

KRIMBAS, C. B. AND LOUKAS, M. 1980. The inversion polymorphism of Drosophila subobscura. Evol. Biol., 12, 163234.

KRIMBAS, C. B. AND LOUKAS, M. 1984. Evolution of the obscura group Drosophila species. I. Salivary chromosomes and quantitative characters in $D$. subobscura and two closely related species. Heredity, 53, 469-482.
LAURIE-AHLBERG, C. C., WILTON, A. N., CURTSINGER, J. W. AND EMIGH, T. H. 1982. Naturally occurring enzyme activity variation in Drosophila melanogaster. I. Sources of variation for 23 enzymes. Genetics, 102, 191-206.

LOUKAS, M., KRIMBAS, C. B., MAVRAGNI-TSIPIDOU, P. AND KASTRITSIS, C. D. 1979. Genetics of Drosophila subobscura populations. VIII. Allozyme loci and their chromosome maps. J. Hered., 70, 17-26.

MATHER, K. AND JINKS, J. L. 1971. Biometrical Genetics, 2nd edn. Chapman and Hall, London.

Olvera, O., POWEll, J. R., DE la ROSA, M. E., SAlCEdA, V. M., GASO, M. I., GUZMAN, J., ANDERSON, W. W. AND LEVINE, L. 1979. Population genetics of Mexican Drosophila. VI. Cytogenetic aspects of the inversion polymorphism in Drosophila pseudoobscura. Evolution, 33, 381395 .

PINKSER, W. AND SPERLACH, D. 1981. Geographic pattern of allozyme and inversion polymorphism on chromosome $\mathrm{O}$ of Drosophila subobscura and its evolutionary origin. Genetica, 57, 51-64.

PREvosti, A., GARCIA, M. P., SERRA, L., AGUAdE, M., RIBO, G. AND SAGARRA, E. 1983. Association between allelic isozymes alleles and chromosomal arrangements in European populations and Chilean colonizers of Drosophila subobscura. In Rattazzi, M. C., Scandalios, J. G. and Whitt, G. S. (eds) Isozymes: Current Topics in Biological and Medical Research, vol. 10, Alan R. Liss, Inc., New York, pp. 171-191.

RENDEL, J. M. 1979. Canalization and selection. In Thompson, J. N. Jr. and Thoday, J. M. (eds) Quantitative Genetic Variation, Academic Press, Inc., London, pp. 139-156.

SCHARLOO, w. 1964. Mutant expression and canalization. Nature, 203, 1095-1096.

SHRIMPTON, A. E. AND ROBERTSON, A. 1988a. The isolation of polygenic factors controlling bristle score in Drosophila melanogaster. I. Allocation of third chromosome sternopleural bristle effects to chromosome sections. Genetics, $118,437-443$.

SHRIMPTON, A. E. AND ROBERTSON, A. 1988b. The isolation of polygenic factors controlling bristle score in Drosophila melanogaster. II. Distribution of third chromosome bristle effects within chromosome sections. Genetics, 118, 445459.

SOKAL, R. R. AND ROHLF, F. J. 1981. Biometry, 2nd edn. W. H. Freeman, San Francisco.

SPERLICH, D., FEUERBACH-MRAVLAG, H., LANGE, P., MICHAELIDIS, A. AND PENTZOS-DAPONTE, A. 1977. Genetic load and viability distribution in central and marginal populations of Drosophila subobscura. Genetics, 86, $835-848$.

SVED, J. A. AND MAYO, O. 1970. The Evolution of Dominance. In K. Kojima (ed.) Mathematical Topics in Population Genetics, Springer-Verlag, Berlin, pp. 289-316.

TEMPLETON, A. R. 1982. Adaptation and the integration of evolutionary forces. In R. Milkman (ed.) Perspectives on Evolution, Sinauer Associates, Inc., Massachusetts, pp. 1531.

TEPPER, C. S., RICHMOND, R. C., TERRY, A. L. AND SENIOR, A. 1982. Studies of esterase 6 in Drosophila melanogaster. XI. Modification of esterase 6 activity by unlinked genes. Genet. Res. Camb., 40, 109-125.

TEPPER, C. S., TERRY, A. L., HOLMES, J. E. AND RICHMOND, R. C. 1984. Studies of esterase 6 in Drosophila melanogaster. XIV. Variation of esterase 6 levels controlled by unlinked genes in natural populations. Genet. Res. Camb., 43, 181190. 
THODAY, J. M. 1961. Location of polygenes. Nature, 191, 368370.

THODAY, J. M. 1979. Polygene mapping: Uses and limitations. In Thompson, J. N. Jr. and Thoday J. M. (eds) Quantitative Genetic Variation, Academic Press, Inc., London, pp. 219233.

THODAY, J. M. AND THOMPSON, J. N. JR. 1976. The number of segregating genes implied by continuous variation. Genetica, 46, 335-344.

THODAY, J. M. AND THOMPSON, J. N. JR. 1984. Polygene polymorphism affecting wing vein formation in a natural population of Drosophila melanogaster. Heredity 53, 635642.

THOMPSON, J. N. JR. 1973. General and specific effects of modifiers of mutant expression. Genet. Res. Camb., 22, 211-215.

THOMPSON, J. N. JR. 1974. Studies on the nature and function of polygenic loci in Drosophila. I. Comparison of genomes from selection lines. Heredity, 33, 373-387.

THOMPSON, J. N. JR. $1975 a$. Studies on the nature and function of polygenic loci in Drosophila. III. Veinlet modifiers having region-specific effects upon the vein pattern. Genetics, $81,387-402$.

THOMPSON, J. N. JR. $1975 b$. Quantitative variation and gene number. Nature, 258, 665-668.

THOMPSON, J. N. JR. 1976. Evidence for polygenes. Nature, 261,526

THOMPSON, J. N. JR. AND SPIVEY, W. E. 1984. Organization of polygenic systems: Cell death modifiers from natural populations of Drosophila melanogaster. Genet. Res., Camb., 44, 261-269.
THOMPSON, J. N. JR. AND THODAY, J. M. 1972. Modification of dominance by selection in the homozygote. Heredity, $29,285-292$.

THOMPSON, J. N. JR. AND THODAY, J. M. 1974. A definition and standard nomenclature for "polygenic loci". Heredity, 33, 430-437.

THOMPSON, J. N. JR. AND WOODRUFF, R. C. 1982. Polygenic analysis of pattern formation: Interdependence among veins in the same compartment of the Drosophila wing. Genetica, 60, 71-76.

TURNER, J. R. G. 1977. Butterfly Mimicry: The Genetical Evolution of an Adaptation. Evol. Biol., 10, 163-206.

WILTON, A. N., LAURIE-AHLBERG, C. C., EMIGH, T. H. AND CURTSINGER, J. W. 1982. Naturally occurring enzyme activity variation in Drosophila melanogaster. II. Relationships among enzymes. Genetics, 102, 207-221.

ZAPATA, C., ALVAREZ, G., DOSIL, M. AND FONTDEVILA, A. 1986. Genetic coadaptation in the chromosomal polymorphism of Drosophila subobscura. II. Changes of gametic disequilibrium in experimental populations. Genetica, 71, 149-160.

ZAPATA, C., SANTOS, M. AND ALVAREZ, G. 1982. Origin of inversions and Wallace's rule of triads. Evolution 36, 407409. 